\title{
As concepções de letramentos na formação de professores de FLE em contexto amazônico
}

\author{
Stéphanie Soares Girão*
}

\begin{abstract}
Resumo
Este artigo tem como objetivo principal analisar as concepções de letramentos descritas no projeto político-pedagógico (PPPC) da Licenciatura em Letras-Língua e Literatura Francesa da Universidade Federal do Amazonas (UFAM), bem como as concepções de letramentos dos professores do curso. A partir do objetivo principal, pretende-se identificar e discutir as perspectivas de letramentos adotadas, articulando os conceitos de letramentos inscritos no documento com aqueles abordados pelos professores da licenciatura. Esta é uma pesquisa qualitativa, cujo procedimento metodológico está fundamentado na análise documental e em entrevistas, portanto, o trabalho se concentra no projeto político-pedagógico de curso, mais especificamente, em duas versões das matrizes curriculares (MC 2013 e MC 2016). Como suporte teórico, o artigo apresenta questões ligadas aos Novos Estudos de Letramento, mais detidamente sobre letramento acadêmico (LEA; STREET, 1998; 2006). Os resultados revelam que os documentos analisados estão fundamentados em uma perspectiva de modelo autônomo de letramento, com características do modelo de hablidades e de socialização acadêmica, enquanto que o discurso da maioria dos docentes está alinhado à perspectiva de letramento ideológico. Finalmente, apresentamos este diagnóstico no sentido de sinalizar direções quando da reformulação de um próximo currículo ou matriz curricular, de forma a alinhá-los com as concepções e práticas de letramento acadêmico do corpo docente.

Palavras-chave: Letramento acadêmico. Modelos de letramento. Currículo. Formação de professores. FLE.
\end{abstract}

\section{Les conceptions de littéracies dans la formation de professeurs de FLE dans un contexte amazonien}

\section{Résumé}

Cet article a pour but d'analyser les conceptions de littéracies présentes dans le curriculum de la Licence en Français Langue Étrangère (FLE) de l'Université Fédérale d'Amazonas (UFAM), ainsi que les conceptions de littéracies présentes dans les discours des professeurs qu'y travaillent. Il s'agit d'une recherche qualitative, dont la méthodologie passe par l'analyse de documents et d'entretiens avec les professeurs de la Licence. En s'appuyant sur le cadre théorique des $\mathrm{New}$ Literacy Studies, particulièrement des littéracies universitaires (LEA; STREET, 1998; 2006), les résultats montrent que la conception de littéracies présente dans le curriculum s'inscrit dans le modèle autonome de littéracie (STREET, 1984; 2014), spécialement le modèle d'habilités et de socialisation universitaire, contrairement aux discours des professeurs, qui valorisent la perspective de littéracie universitaire (idéologique). Enfin, le diagnostic réalisé peut offrir quelques directions pour la reformulation du curriculum, priorisant les conceptions des littéracies universitaires, déjà adoptées par les professeurs.

Mots-clés: Littéracies universitaires. Modèles de littéracies. Curriculum. Formation de professeurs. FLE.

Recebido: 19/03/2019

Aceito: 24/07/2019

* Universidade Federal do Amazonas (UFAM). Professora de língua e literatura francesa. Doutoranda em Linguística Aplicada no programa de pós-graduação em Linguística Aplicada da Universidade Estadual de Campinas (UNICAMP). 


\section{Contexto histórico da formação de professores de francês no norte brasileiro}

No Brasil, os estudos sobre letramento têm ampliado seu terreno de pesquisa nos cursos de formação de professores de línguas estrangeiras, principalmente pelas políticas de expansão do acesso às universidades e pelas políticas de internacionalização das universidades públicas. Uma parte dessas pesquisas dedica-se à questão dos gêneros orais e escritos, à formação do perfil profissional e à escrita científica, por exemplo. Na seara desses estudos, o presente artigo tem interesse em investigar as concepções de letramento descritas no projeto político-pedagógico de curso (doravante PPPC) da Licenciatura em Letras-Língua e Literatura Francesa da Universidade Federal do Amazonas (doravante UFAM), em relação às concepções de letramento dos professores do curso.

A região Norte é formada por seis estados dos quais cinco - Acre, Amapá, Amazonas, Pará e Roraima - possuem cursos de formação inicial de professores de Francês como Língua Estrangeira (doravante FLE) desde 1965, quando foi criada a Licenciatura em Letras-Língua e Literatura Francesa na UFAM. Juntas, as seis principais licenciaturas dessa região recebem em média 200 novos estudantes por ano.

A quantidade de cursos superiores oferecidos é reflexo da forte presença da língua francesa na região, principalmente quando consideramos a fronteira geográfica do estado do Amapá com a Guiana Francesa, território ultramarino francês, e, mais recentemente, o fluxo migratório de haitianos. Além da língua, a influência da cultura francesa foi, historicamente, símbolo de modernização urbana, atingindo seu auge no final do século XIX, momento em que o ciclo da borracha aumentou a produtividade econômica da região. Mas, assim como o ciclo da borracha, a influência da língua e cultura francesas declinou, abrindo espaço para o fortalecimento de culturas outras, locais e estrangeiras. Contudo, nos últimos anos, a língua francesa vem retomando seu espaço no ensino básico das escolas públicas, a exemplo de Manaus, com a inauguração da escola bilíngue português/francês, a Escola Estadual José Carlos Mestrinho, no início de 2017, e de Macapá, com o Projeto Escola Intercultural Bilíngue de Fronteira, inaugurado também em 2017.

Com essa nova realidade, identificamos a necessidade de compreender alguns aspectos da formação de professores de FLE na região, portanto, a análise aqui apresentada é reflexo de um mapeamento realizado entre os anos de 2010 e 2016, no contexto de formação de professores de FLE na UFAM, durante as aulas ministradas nos cursos de prática escrita e na elaboração da matriz curricular de 2016. Tecemos então uma análise entre as duas matrizes curriculares ainda em vigor, considerando as mudanças nas práticas de letramento acadêmico ocorridas a partir da matriz curricular de 2016, contrapondo as concepções de letramento descritas no PPPC com as concepções de letramento dos professores da licenciatura em questão.

Enfim, ao considerarmos as singularidades que atravessam a região Norte do país, bem como o contexto da formação de professores de FLE nessa região, entendemos que é tempo de lançar um olhar mais cuidadoso à formação desses professores, especialmente no que diz respeito às concepções de letramento nessa formação.

\section{Questões de currículo e metodologia da análise}

Sabemos que há uma enorme diferença entre o universo educacional do Ensino Básico brasileiro e aquele do Ensino Superior, e, conhecendo as especificidades das atividades acadêmicas, não é difícil perceber a dificuldade dos estudantes quando se trata da adaptação aos códigos do trabalho intelectual na universidade (DELCAMBRE; LAHANIER-REUTER, 2010). Para atenuar essas diferenças, uma grande parte das universidades cria estratégias pedagógicas cujos objetivos são concebidos para inserir 
os estudantes recém-chegados nas práticas de leitura e escrita em contexto acadêmico, iniciando assim um processo de aculturação (ASSIS; BOCH; RINCK, 2015) desde o primeiro ano de formação. ${ }^{1}$

Essas estratégias podem figurar na formação através de projetos e atividades extensionistas, por exemplo, mas estão presentes nos currículos universitários principalmente por meio de disciplinas específicas para trabalhar a escrita acadêmica, como veremos adiante. ${ }^{2}$ No contexto brasileiro, os currículos universitários são organizados em um PPPC, por exigência do Ministério da Educação (MEC), orientados por resoluções do Conselho Nacional de Educação. Não obstante, esse documento não é criado apenas para organizar o conhecimento a ser trabalhado nos cursos superiores, mas é, principalmente, uma "prática discursiva [...], prática de poder, [...] uma espécie de significação, de atribuição de sentidos [...]” (LOPES; MACEDO, 2011, p. 41) e, portanto, atravessado pelos discursos que o formam. ${ }^{3}$

Isso posto, este artigo contempla uma análise de natureza qualitativa, que utiliza como corpus os documentos reguladores da Licenciatura em Letras-Língua e Literatura Francesa da UFAM: o PPPC do curso; a matriz curricular de 2013; e a de 2016 (doravante MC); e também as entrevistas realizadas com quatro professores da licenciatura do curso. ${ }^{4}$ Os documentos foram coletados na própria instituição, em 2018, e as entrevistas foram realizadas por meio virtual em 2019.

Para a análise dos dados, realizamos um recorte teórico que se insere no campo dos letramentos acadêmicos, utilizando como categorias de análise os conceitos-chave desenvolvidos por Brian V. Street $(1984 ;$ 2014) sobre modelo autônomo e modelo ideológico de letramento. Segundo o teórico, o modelo autônomo 'tende a se basear na forma de letramento do 'texto dissertativo', prevalente em certos círculos sociais e acadêmicos [...]” (STREET, 2014, p. 44) e tem foco principalmente nos aspectos técnicos e normativos da escrita, descontextualizados socialmente. Já o modelo ideológico de letramento se concentra em "práticas sociais específicas de leitura e escrita. Reconhecem a natureza ideológica e, portanto, culturalmente incrustada dessas práticas” (STREET, 2014, p. 44).

Além dos modelos autônomo e ideológico, também utilizamos como categorias de análise os conceitos deles derivados e definidos por Lea e Street (1998; 2006), quais sejam modelos das habilidades de estudo, modelo de socialização acadêmica e modelo do letramento acadêmico:

o primeiro modelo considera que os estudantes adquirem habilidades de uso da escrita e podem transferir seus conhecimentos sobre leitura e escrita sem grandes problemas de um contexto para outro. O segundo modelo postula processos de aculturação dos estudantes pela universidade e considera que eles adquirem, com os professores, os modos de falar, escrever e pensar acadêmicos e passam a usar a escrita como típicos membros da esfera acadêmica. Finalmente, o terceiro modelo, ao qual os autores se filiam, esclarece certas especificidades das práticas acadêmicas de uso da escrita, tais como a construção de sentidos, identidades, poder e autoridade, enfatizando que o que é considerado conhecimento construído e validado depende da área de conhecimento e dos contextos acadêmicos particulares nos quais tal conhecimento circula. (VIANNA et al SITO; VALSECHI; PEREIRA, 2016, p. 48).

Para não nos distanciarmos do objetivo central deste artigo, não nos estenderemos em uma revisão bibliográfica sobre os Novos Estudos de Letramento (NEL), contudo, os significados das categorias escolhidas serão retomados ao longo da análise do corpus. ${ }^{5}$

1 Entendemos o processo de aculturação como aquele em que um indivíduo é inserido em uma determinada cultura.

2 Neste artigo, disciplinas são entendidas como os cursos ofertados nas matrizes curriculares.

3 Disponível em: <http://portal.mec.gov.br/observatorio-da-educacao/323-secretarias-112877938/orgaos-vinculados82187207/12991-diretrizes-curriculares-cursos-de-graduacao>. Acesso em: 5 fev. 2019.

$4 \mathrm{O}$ corpo docente da licenciatura é formado por seis professores, dos quais quatro participaram da entrevista.

5 Sobre esse assunto, ver também Kleiman (1995), Kleiman e Assis (2016) e Fumo e Girão (2018). 


\subsection{Histórico da licenciatura e matrizes curriculares}

Como um dos primeiros cursos de formação de professores de FLE da região Norte, a Licenciatura em Letras - Língua e Literatura Francesa da UFAM, ao longo de 54 anos de existência, teve cinco versões de MCs: a dos anos de 1965, 1974, 2000, 2013 e 2016, respectivamente.

Apesar das diversas MCs, até 2014, não havia sido encontrada na instituição nenhuma proposta curricular da licenciatura, o que motivou a criação e publicação do PPPC no mesmo ano e ao qual foi anexada a MC de 2013. Porém, apesar de possuir um PPPC e uma MC recentes, em 2016, o Núcleo Docente Estruturante criou novas disciplinas para o curso, o que culminou na MC de 2016, implementada no mesmo ano. Nossa análise, portanto, se concentrará nas duas últimas versões de $\mathrm{MC}$, pois ambas ainda estão em vigor.

Para identificar em quais momentos os estudantes passam pelo processo de aculturação acadêmica, realizamos a leitura das ementas e dos objetivos das disciplinas das duas versões das MCs (2013 e 2016) em busca de termos relacionados à escrita acadêmica. A partir dos resultados obtidos, pudemos identificar as disciplinas com foco na escrita acadêmica (que serão analisadas na próxima seção) e a sua carga horária total. Vejamos, pois, em quais momentos essa formação é ofertada:

\begin{tabular}{l|c|c|c|c} 
Tabela $\mathbf{1}-$ Matrizes curriculares \\
Versão da matriz curricular & $\mathbf{1}^{\mathbf{0}}$ ano & $\mathbf{2}^{\mathbf{o}}$ ano & $\mathbf{3}^{\mathbf{o}}$ ano & $\mathbf{4}^{\mathbf{0}}$ ano \\
\hline 2013 & $180 \mathrm{~h}^{1}$ & $60 \mathrm{~h}$ & $\mathrm{X}$ & $210 \mathrm{~h}$ \\
\hline 2016 & $180 \mathrm{~h}$ & $30 \mathrm{~h}$ & $60 \mathrm{~h}$ & $510 \mathrm{~h}$
\end{tabular}

Fonte: Elaboração própria.

Na Tabela 1, fica claro que a matriz curricular de 2016 não só expandiu consideravelmente a quantidade de carga horária dedicada às atividades de escrita acadêmica como a distribuiu ao longo dos quatro anos de formação, o que não acontece na matriz curricular de 2013, em que a carga horária está concentrada no primeiro e no último ano de formação. Porém, a diferença que mais se destaca entre as duas matrizes é o aumento expressivo de 300 horas na carga horária do quarto ano da MC 2016, reflexo da criação de três disciplinas direcionadas ao trabalho de conclusão de curso (doravante TCC).

Tais disciplinas são inexistentes na versão de 2013, contudo, a disciplina de Estágio Supervisionado solicita a produção de uma monografia como TCC, dividindo a carga horária com atividades específicas de formação profissional docente, como a regência de aulas e a produção de material didático, por exemplo.

\subsection{Componentes curriculares: disciplinas, ementas e objetivos}

Como vimos, a licenciatura tem duas matrizes curriculares ainda em vigor, as quais possuem diferenças tanto na carga horária quanto na distribuição das disciplinas ao longo da formação. Essas diferenças são resultado de alterações nas ementas, objetivos e referências bibliográficas de algumas disciplinas voltadas para aquisição de língua, letramento acadêmico e formação de professor, dentre as quais algumas serão objeto desta seção, assim como da criação de novas disciplinas para a realização do TCC, que discutiremos na seção 2.3 . 
A análise do PPPC revelou que, ao longo dos quatro anos de formação, a aculturação acontece de maneira orgânica e constante no âmbito da maioria das disciplinas, com leitura e escrita de textos próprios do universo acadêmico (resenhas e resumos, por exemplo), bem como a existência de práticas (avaliativas) voltadas aos gêneros orais formais públicos (SCHNEUWLY; DOLZ, 2004), como os seminários. No entanto, para este artigo, analisamos as disciplinas cujo interesse de estudo é a formação para a escrita acadêmica e identificamos três eixos disciplinares que contemplam esse interesse: a) escrita acadêmica em português; b) escrita acadêmica em francês; e c) escrita científica.

As disciplinas do eixo a) escrita acadêmica em português se repetem em ambas as MCs: oferecidas no primeiro ano de formação, apresentam ementas, objetivos e carga horária idênticos, com o objetivo de, entre outras ações, "aprimorar o seu desempenho na produção escrita, habilitando-se a produzir textos amparados nos princípios de organização, unidade, coerência e concisão" (UNIVERSIDADE FEDERAL DO AMAZONAS, 2014, p. 29).

Nas ementas dessas disciplinas, lemos: "O parágrafo como unidade de composição: formas de constituição, características e qualidades. A frase e suas características no interior do parágrafo. Produção de parágrafos. Redação: Processo e estrutura. Produção de textos" (UNIVERSIDADE FEDERAL DO AMAZONAS, 2014, p. 29) e ainda "Produção de textos: Descrição, narração, dissertação e argumentação. Revisão gramatical aplicada ao texto" (UNIVERSIDADE FEDERAL DO AMAZONAS, 2014, p. 29).

Os itens citados revelam que as disciplinas foram concebidas com características muito próximas ao modelo de habilidades de estudo (LEA; STREET, 1998; 2006), pois buscam uma equivalência na fluência da escrita em língua portuguesa dos estudantes recém-ingressos na licenciatura, com especial ênfase no uso da gramática normativa e da estrutura padronizada dos textos, priorizando, assim, um modelo autônomo de letramento (STREET, 1984; 2014).

Em nossa análise, passamos ao eixo b) escrita acadêmica em francês. Na MC de 2013, as ementas e os objetivos das disciplinas indicam como produção textual a "redação acadêmica" (UNIVERSIDADE FEDERAL DO AMAZONAS, 2014, p. 41) e a "redação acadêmica: escrita de monografia" (UNIVERSIDADE FEDERAL DO AMAZONAS, 2014, p. 47), respectivamente, no terceiro e no quarto semestres da formação (segundo ano). O documento não deixa claro quais gêneros acadêmicos são compreendidos por "redação acadêmica", porém a monografia é solicitada sem, contudo, definir os parâmetros dessa escrita.

Questionado sobre a escrita de monografia na disciplina de Prática Escrita em Língua Francesa, um dos professores da licenciatura responde: "Na prática, nunca foi possível trabalhar a monografia como propõe a ementa de Prática Escrita em Língua Francesa III, tanto pela carga horária da disciplina quanto pelo nível linguístico dos estudantes, por isso foi feita a alteração da disciplina em 2016." (P1). ${ }^{6}$ De fato, na matriz curricular de 2016, há uma redução da carga horária nas práticas de escrita acadêmica em francês e há também uma adequação do gênero ao nível linguístico (em língua francesa) dos estudantes, assim, nessa versão da MC, é solicitado aos estudantes que produzam um "resumo acadêmico na língua-alvo" (UNIVERSIDADE FEDERAL DO AMAZONAS, 2016, p. 16) no quarto semestre.

Nas disciplinas desse eixo, notamos a tentativa de ajustar a escrita dos estudantes aos modelos dos gêneros acadêmicos tradicionais, no caso em análise, o resumo em língua estrangeira, solicitado principalmente em trabalhos acadêmicos de teor mais científico, como artigos, por exemplo.

No que tange à escrita científica (eixo c), encontramos algumas disciplinas que têm foco exclusivo na formação para a escrita científica e para a escrita da monografia, sendo a primeira ofertada no primeiro semestre nas duas versões de matriz curricular. Na MC de 2013, a disciplina apresenta como objetivos:

6 Por razões éticas, os nomes dos professores entrevistados foram substituídos pela inicial P e numerais. 
Compreender a especificidade do trabalho universitário como processo de produção e apropriação do conhecimento científico no campo das ciências humanas. Tematizar a leitura e a escrita de textos na Universidade considerando alguns de seus aspectos teórico-metodológicos, a fim de desenvolver competências e habilidades que ajudem os (as) alunos (as) a interagir de maneira crítica frente às demandas de estudos acadêmicos. (UNIVERSIDADE FEDERAL DO AMAZONAS, 2014, p. 31).

Os objetivos dessa disciplina relacionam leitura e escrita como processos interdependentes, busca uma formação crítica do estudante e sugere, ainda que indiretamente, o modelo de letramento acadêmico (LEA; STREET, 1998; 2006), ao pressupor uma relação entre identidade, poder, autoridade e produção de sentido na academia, considerando, assim, o pensamento crítico como uma habilidade a ser desenvolvida .

Na MC de 2016, a disciplina tem por objetivo "fornecer os pressupostos básicos de iniciação à pesquisa para elaboração de trabalhos escolares/relatórios, aplicando os passos da metodologia científica para uma melhor convivência acadêmica e aumento do nível de aproveitamento nos estudos [...]" (UNIVERSIDADE FEDERAL DO AMAZONAS, 2016), ou seja, prioriza claramente uma retomada dos modelos de habilidade de estudos e socialização acadêmica (LEA; STREET, 1998; 2006) em detrimento de um modelo de letramento acadêmico (presente na versão da disciplina da MC de 2013).

De volta à MC de 2013, só será possível encontrar outra disciplina com foco na escrita científica no último semestre do curso. Porém, o que nos chama a atenção é que tal disciplina é de estágio e demanda, além da regência de classe (prática comum de licenciados em fase final de formação), a produção de textos e atividades de naturezas diversas e igualmente complexas: "Regência de classe. Produção de material didático. Plano de aula. Relatório de estágio. Redação de trabalho de conclusão de curso." (UNIVERSIDADE FEDERAL DO AMAZONAS, 2014, p. 63). Assim, as mesmas razões que levaram à mudança da ementa da disciplina de prática escrita em língua francesa, citada anteriormente, levaram à criação de disciplinas específicas direcionadas à escrita do trabalho monográfico na MC de 2016.

A análise apresentada revela que há uma preocupação imediata com a aculturação dos estudantes no que se refere à escrita acadêmica, alinhada ao modelo de letramento autônomo, especialmente no primeiro ano de formação, como vimos na Tabela 1. De acordo com Angela Kleiman, “esse é o modelo que hoje em dia é prevalente em nossa sociedade e que se reproduz, sem grandes alterações, desde o século passado [...]" (KLEIMAN, 1995, p. 21) e que está ligado a uma concepção de ensino homogeneizadora, que prioriza a reprodução de estruturas e normas do texto escrito, modelo presente ainda hoje em alguns currículos universitários.

A investigação também nos revela que as práticas de letramento diminuem consideravelmente no segundo e terceiro anos de formação, recebendo, por fim, uma ampla carga horária no último ano da licenciatura, quando é solicitado aos estudantes que, sob a orientação de um professor, produzam um trabalho monográfico, também conhecido como TCC. Devido à existência dessas disciplinas unicamente na matriz curricular de 2016, dedicaremos a próxima seção à análise delas.

\subsection{Modelos de letramento na escrita monográfica}

Partindo do princípio da autonomia, cada universidade prevê, em seu PPPC, uma forma de avaliação final do estudante que se forma, a fim de se aferir a maturidade acadêmica necessária para a obtenção do título de graduação. Dentro do contexto acadêmico-científico, tradicionalmente, os modos de avaliação são escritos, assim, o TCC deve ser apresentado em sua versão escrita e, em algumas instituições, também deve ser apresentado oralmente. 
No PPPC em análise, o trabalho de conclusão de curso requer a escrita de uma monografia "orientada por um professor do curso, que acompanhará o estudante em todas as fases de elaboração do texto" (UNIVERSIDADE FEDERAL DO AMAZONAS, 2014, p. 24), e, além da defesa oral, o TCC deverá ser "redigido numa linguagem que demonstre o domínio da técnica de preparação de textos acadêmicos e da habilidade de se manifestar por meio da língua escrita de acordo com a norma padrão" (UNIVERSIDADE FEDERAL DO AMAZONAS, 2014, p. 25). Mais uma vez, o modelo de habilidade de estudo (LEA; STREET, 1998; 2006) aparece em destaque no documento.

Buscando preencher a lacuna da escrita monográfica existente na MC de 2013, foram criadas três disciplinas que passaram a vigorar a partir da MC de 2016, são elas: Trabalho de conclusão de curso I, Trabalho de conclusão de curso II e Trabalho de conclusão de curso III. Vejamos o que propõem as três disciplinas:

Tabela 2 - Trabalho de conclusão de curso

\begin{tabular}{|c|c|c|}
\hline TCC I & TCC II & TCC III \\
\hline 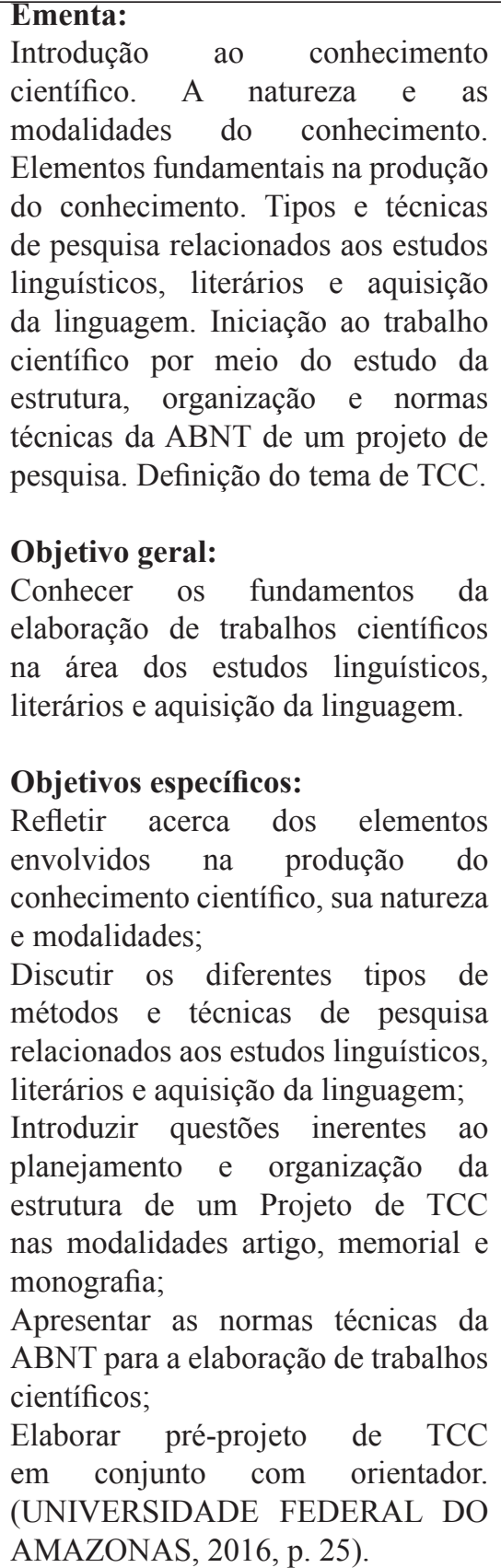 & $\begin{array}{l}\text { Ementa: } \\
\text { Desenvolvimento e orientação de } \\
\text { projeto de TCC estabelecido pelo } \\
\text { aluno e seu orientador. O projeto será } \\
\text { avaliado pelo orientador. Normas } \\
\text { técnicas da ABNT. Ética na pesquisa. } \\
\text { Objetivo geral: } \\
\text { Desenvolver o trabalho de conclusão } \\
\text { de curso analisando um determinado } \\
\text { ponto em relação aos estudos } \\
\text { linguísticos, literários, culturais ou } \\
\text { de ensino de francês como língua } \\
\text { estrangeira, que leve em consideração } \\
\text { os conhecimentos teóricos e críticos } \\
\text { obtidos durante o curso e que tenham } \\
\text { sido relevantes na formação do aluno } \\
\text { finalista. } \\
\text { Objetivos específicos: } \\
\text { Desenvolver a pesquisa sob os } \\
\text { auspícios do orientador; } \\
\text { Sintetizar a pesquisa proposta, } \\
\text { os fatos, as leituras realizadas e } \\
\text { acontecimentos que constituíram a } \\
\text { trajetória acadêmico-profissional do } \\
\text { aluno; } \\
\text { Concluir o projeto do TCC para o } \\
\text { orientador do curso sob a forma de } \\
\text { texto dissertativo, analítico e crítico. } \\
\text { (UNIVERSIDADE FEDERAL DO } \\
\text { AMAZONAS, 2016, p. 26). }\end{array}$ & $\begin{array}{l}\text { Ementa: } \\
\text { Defesa do projeto proposto pelo aluno } \\
\text { sob a forma de texto monográfico } \\
\text { perante a banca examinadora. } \\
\text { Objetivo geral: } \\
\text { Ajustar aspectos gerais do projeto } \\
\text { de TCC a partir das orientações } \\
\text { recebidas. } \\
\text { Objetivos específicos: } \\
\text { Definir calendário de defesas de TCC; } \\
\text { Estabelecer membros para a compor } \\
\text { banca examinadora; } \\
\text { Apresentar versão final do TCC à } \\
\text { banca examinadora do curso sob a } \\
\text { forma de texto dissertativo, analítico } \\
\text { e crítico. (UNIVERSIDADE } \\
\text { FEDERAL DO AMAZONAS, 2016, } \\
\text { p. 27). }\end{array}$ \\
\hline
\end{tabular}

Fonte: Elaboração própria. 
De acordo com Kleiman, no modelo autônomo de letramento, a escrita é "um produto completo em si mesmo, que não estaria preso ao contexto de sua produção para ser interpretado [...]" (KLEIMAN, 1995, p. 22) e que apresenta três características: "1. a correlação entre a aquisição da escrita e o desenvolvimento cognitivo; 2. a dicotomização entre a oralidade e a escrita; 3. a atribuição de 'poderes' e qualidades intrínsecas à escrita, e por extensão, aos povos ou grupos que a possuem." (KLEIMAN, 1995, p. 22).

Dessa forma, apesar de propor a reflexão acerca da natureza e da ética no trabalho científico, as três disciplinas priorizam majoritariamente o estudo da forma e das normas relativas à produção de um texto acadêmico, ressaltando inclusive o uso das normas técnicas criadas com a finalidade de formatar a escrita científica. Isso significa que, no nível curricular, ou seja, o discurso presente no PPPC, a perspectiva adotada na licenciatura é a do modelo autônomo de letramento.

Como vimos ao longo deste artigo, o currículo é parte integrante da formação escolar, responsável por organizar as disciplinas e sintetizar as diretrizes dos cursos. No entanto, o PPPC é apenas um dos elementos presentes na prática pedagógica, sendo reiterado, superado ou mesmo rompido pelos atores do processo formativo: estudantes e professores.

De acordo com as orientações do PPPC, a escrita da monografia não é um processo solitário, mas, antes, passa pelo acompanhamento contínuo de um professor orientador. Por esse motivo, entrevistamos os professores que atuaram nas disciplinas de TCC. Quando questionados sobre suas experiências nas disciplinas, os professores anunciam suas concepções sobre a escrita acadêmica:

A meu ver, a categoria "escrita acadêmica" é bastante problemática na medida em que é separada do pensamento crítico. O que realmente importa não é que os alunos aprendam a respeitar tim-tim por tim-tim a gramática normativa e as normas da ABNT, mas que desenvolvam uma subjetividade crítica e pesquisadora (o que incidirá então sobre a qualidade de sua escrita). A sensação que se tem hoje lendo boa parte dos "escritos acadêmicos" é de um vazio de pensamento recoberto por citações e outros cacoetes. Não é para isso que desejo preparar nossos alunos. (P2).

Outro professor aponta que a escrita acadêmica "é parte de um processo muito longo, [...] tem certas regras, e isso se aprende. Agora aprender a escrever, escrever com lógica, coerência é também aprender a pensar. Isso se aprende desde pequenininho" (P3). O mesmo professsor completa:

Outra coisa: apenas obrigar a escrever não resolve nada. $\mathrm{O}$ aluno deve e pode escrever sobre o que lhe interessa, lhe toca, lhe diz respeito, lhe importa ou the emociona. Sem isso é jogar tempo e trabalho fora. [...] Deveria ser isso desde o ensino básico, essa coisa de tocar o aluno [...] o aluno deveria ser instado, seduzido - eu diria — a escrever. (P3).

O depoimento dos entrevistados demonstra que, apesar do que o PPPC e as disciplinas propõem como modelo de letramento (autônomo), suas concepções sugerem que o modelo de letramento acadêmico (ideológico) é o que mais permeia suas práticas pegagógicas, mesmo que essas não se furtem às considerações sobre a norma e a forma textual. No entanto, há aqueles que ainda sustentam o discurso do déficit:

São vários os desafios, porém os mais recorrentes partem do desempenho e interesse do próprio aluno para desenvolver sua escrita. Os estudantes tendem a apresentar dificuldades básicas no momento da construção de seu próprio texto, acredito que tal empecilho é provindo do ensino básico não tão bem trabalhado. (P4).

No artigo "Práticas de leitura e escrita: modos de dizer e atribuir identidades", publicado em 2016, Rodrigues, Fonseca e Martins apresentam a relação do modelo de letramento acadêmico com a prática docente. Para os autores, "este modelo pode englobar os anteriores [...]" (RODRIGUES; FONSECA; 
MARTINS, 2016, p. 333), mas são principalmente "práticas epistemológicas [que] permitem trabalhar o protagonismo do estudante, percebendo que o novo público de ingressantes no ensino superior só tem a enriquecer a dimensão social da universidade [...]" (RODRIGUES; FONSECA; MARTINS, 2016, p. 334).

Questionados sobre a contribuição das disciplinas de TCC para a formação dos estudantes e para a escrita acadêmica, os professores entrevistados reconhecem que o PPPC e as MCs priorizam majoritariamente o aprendizado da forma e da norma textual em detrimento do conteúdo, porém o surgimento de novas disciplinas na MC de 2016 foi fundamental para a criação de espaços em que o protagonismo e a subjetividade dos estudantes pudessem ser exercidos, apesar de que esse avanço requer ainda um trabalho com muitos desafios a serem superados:

[...] as disciplinas de TCC podem constituir sim um espaço privilegiado para a constituição dessa subjetividade, já que colocam o discente diante desse belo desafio: escrever seu "próprio" texto. [...] É claro que as dificuldades que boa parte dos discentes apresenta com a "escrita acadêmica" atrapalham o desenvolvimento do processo, mas, insisto, o principal não está aí e sim na dificuldade de construir uma pesquisa significativa, fazer boas leituras de bons textos, interpretar dados e enunciados, pensar de maneira crítica e criativa (mais do que produtiva e reprodutiva) e redigir um texto relevante (nesse caso, se ele fugir das normas da escrita acadêmica num devir artístico ou mesmo coloquial, tant pis ${ }^{7}$ pra escrita acadêmica!). (P2).

Perguntamos aos entrevistados sobre outras alternativas para a promoção de práticas de escrita acadêmica que são realizadas no curso, e, nas respostas dos professores, o currículo aparece como principal projeto, seguido dos programas de iniciação científica (PIBIC):

Acho que, de alguma maneira, todas as disciplinas devem contribuir para a construção dessa subjetividade crítica e pesquisadora e, assim, para que os discentes cheguem a escrever bons textos; mas, de maneira mais específica, temos as disciplinas [...] que têm como foco a escrita acadêmica em nosso vernáculo e no francês. Além disso, os PIBICs são evidentemente ocasiões privilegiadas para desenvolvê-la. (P2).

Um dos professores (P3) acredita que, no caso da licenciatura em francês, os cursos propostos atendem à demanda da universidade para a escrita acadêmica, porém sugere que a criação de novos cursos é sempre uma boa alternativa para dar continuidade às práticas de letramento na universidade.

O quarto professor entrevistado complementa: “existem projetos [...] como, por exemplo, o PIBIC, mas que todos os alunos de variados cursos podem participar" (P4), e, no momento da entrevista, percebe uma oportunidade ainda não criada no curso: "Uma ótima sugestão sobre o projeto de extensão na escrita acadêmica... chateada por não ter pensado nisso". (P4).

\section{Perspectivas de letramento acadêmico: considerações finais}

As perspectivas do letramento acadêmico encontram abrigo nas considerações teóricas desenvolvidas por Lea e Street (1998; 2006), juntamente com o grupo de pesquisa sobre os NEL, assim, para Street:

o conceito de práticas de letramento é realmente uma tentativa de lidar com os eventos e com os padrões de atividades de letramento, para ligá-los a uma coisa mais ampla de natureza cultural e social [...]. As práticas de letramento referem-se a essa concepção cultural mais ampla de modos particulares de pensar sobre a leitura e a escrita e de realizálas em contextos culturais. (STREET, 2012, p. 76).

7 Pouco importa. Tradução nossa. 
Para descrever as práticas de letramento em contexto acadêmico, Lea e Street (1998; 2006), com base na análise das expectativas e interpretações dos estudantes e dos professores, indicam três modelos: modelo das habilidades de estudo, modelo de socialização acadêmica e modelo do letramento acadêmico. Juntamente com os modelos de letramento autônomo e letramento ideológico, esses modelos foram utilizados como critérios de análise dos documentos que orientam as disciplinas da licenciatura em questão, o projeto político-pedagógico de curso, a matriz curricular 2013 e a matriz curricular 2016, com o interesse de identificar quais concepções de letramento lhes são subjacentes, tendo como contraponto as concepções de letramento dos professores.

Ao longo da análise dos documentos, identificamos que o processo de aculturação acadêmica se inicia desde o primeiro semestre da formação dos estudantes e se estende, na versão mais recente da $\mathrm{MC}$, ao longo de toda a formação por meio de práticas de leitura (ainda que estas não tenham sido objeto de nossa análise) e de escrita de gêneros típicos da esfera acadêmica, e é consolidada mediante a apresentação de uma monografia solicitada como TCC. Porém, em todos os documentos analisados — PPPC, MC 2013 e MC 2016 — os modelos de letramento subjacentes a essas práticas são orientados pelos conceitos de modelos de habilidade e de socialização acadêmica, inerentes ao modelo autônomo de letramento.

O marco que possibilita a quebra desse paradigma é a criação de disciplinas voltadas exclusivamente para a produção do TCC. A partir do diálogo com o corpo docente da licenciatura, ficou evidente que tais disciplinas possibilitaram não apenas a expansão da carga horária dedicada às práticas de escrita acadêmica, mas oportunizaram um espaço de reflexão sobre as práticas de letramento inspiradas no modelo de letramento acadêmico (ideológico), privilegiando, dentro dessas novas práticas, o protagonismo dos estudantes na elaboração de uma escrita crítica e socialmente contextualizada.

De fato, quando concebidos a partir dos modelos de letramentos acadêmicos, os currículos têm grandes chances de promover espaços de formação crítica na e pela escrita, revelando as subjetividades dos estudantes e a dimensão social da universidade, que tem se expandido nos últimos anos. Isso posto, surge um questionamento: se, como afirmamos no início deste artigo, o currículo é um documento atravessado pelos discursos que o formam, por que a perspectiva dos letramentos acadêmicos, tão corporificada no discurso dos professores, não se reflete nos documentos?

Ora, sabemos que o contexto de construção de um currículo não se define em um único momento, como fica evidenciado nas várias versões de $\mathrm{MC}$, e, uma vez construído, não significa que esse currículo tornar-se-á um produto definitivo. Vimos que, ao longo dos anos, cada vez mais o currículo da licenciatura em Letras-Língua e Literatura Francesa da UFAM foi se reformulando de modo a acompanhar as transformações sociais e epistemológicas do contexto acadêmico. Dessa maneira, esperamos que os resultados deste estudo/diagnóstico contribuam não apenas no sentido de revelar e contrastar as concepções de letramento presentes no currículo e nos discursos dos professores dessa licenciatura, mas também de sinalizar direções quando da reformulação de um próximo currículo ou matriz curricular, alinhando-os com o modelo ideológico de letramento acadêmico já presente nos discursos dos docentes do curso. 


\section{Referências}

ASSIS, J. A.; BOCH, F.; RINCK, F. (org.). Letramento e formação universitária: formar para a escrita e pela escrita. Campinas, SP: Mercado das Letras, 2015.

DELCAMBRE, I.; LAHANIER-REUTER, D. Les littéracies universitaires: influence des disciplines et du niveau d'étude dans les pratiques de l'écrit. Diptyque: l'appropriation des discours universitaires, Presses Universitaires de Namur, n. 18, p. 11-42, 2010. Disponível em: <https://www.leseforum.ch/ fr/myUploadData/files/2010_3_Delcambre_Lahanier.pdf $>$. Acesso em: 7 jan. 2019.

KLEIMAN, A. B. Modelos de letramento e as práticas de alfabetização na escola. In: KLEIMAN, A. B. (org.). Os significados do letramento: uma nova perspectiva sobre a prática social da escrita. Campinas, SP: Mercado de Letras, 1995. p. 15-61.

LEA, M. R.; STREET, B. V. Student writing in high education: an academic literacies approach. Studies in higher education, v. 23, n. 2, p. 157-172, 1998. Disponível em: <https://www.tandfonline. com/doi/abs/10.1080/03075079812331380364>. Acesso em: 7 fev. 2019.

LEA, M. R.; STREET, B. V. The 'academic literacies' model: theory and application. Theory into practice, v. 45, n. 4, p. 368-377, 2006. DOI 10.1207/s15430421tip4504_11. Disponível em: <https:// www.tandfonline.com/doi/abs/10.1207/s15430421tip4504_11>. Acesso em: 7 fev. 2019

LOPES, A. R. C.; MACEDO, E. Teorias de currículo. São Paulo: Cortez, 2011.

RODRIGUES, D. L. D. I.; FONSECA, G. M. R; MARTINS, J. B. Práticas de leitura e escrita: modos de dizer e atribuir identidades. In: KLEIMAN, A. B.; ASSIS, J. A. (org.). Significados e ressignificações do letramento: desdobramentos de uma perspectiva sociocultural sobre a escrita. Campinas: Mercado de Letras, 2016. p. 331-342.

FUMO, Oscar; GIRÃO, Stéphanie S. Práticas de letramento acadêmico em Moçambique: análise de um trabalho de escrita de gêneros. Papéis, Campo Grande, v. 22, n. 43, p. 72-90, 2018. Disponível em: <https://periodicos.ufms.br/index.php/papeis/article/view/6275>. Acesso em: 27 ago. 2019.

SCHNEUWLY, B.; DOLZ, J. (e colab.). Gêneros orais e escritos na escola. Tradução e organização de Roxane Rojo e Glaís S. Cordeiro. Campinas, SP: Mercado das Letras, 2004.

STREET, B.V. Literacy in theory and practice. New York: Cambridge University Press, 1984.

STREET, B. V. Eventos de letramento e práticas de letramento: teoria e prática nos novos estudos do letramento. In: MAGALHÃES, I. (org.). Discursos e práticas de letramento. Campinas, SP: Mercado de Letras, 2012. p. 69-92.

STREET, B. V. Letramento e mudança social: a importância do contexto social no desenvolvimento de programas de letramento. In: LETRAMENTOS sociais: abordagens críticas do letramento no desenvolvimento, na etnografia e na educação. São Paulo: Parábola Editorial, 2014. p. 43-61.

UNIVERSIDADE FEDERAL DO AMAZONAS. Grades curriculares. [200-]. Disponível em: $<$ https://ecampus.ufam.edu.br/ecampus/gradesCurriculares $>$. Acesso em: 17 jan. 2019.

UNIVERSIDADE FEDERAL DO AMAZONAS. Projeto político-pedagógico licenciatura em Letras - língua e literatura francesa. Manaus: UFAM, 2014.

UNIVERSIDADE FEDERAL DO AMAZONAS. Matriz curricular 2016. Manaus: UFAM, 2016.

VIANNA, C. A. D. et al SITO, L.; VALSECHI, M. C.; PEREIRA, L. S. M. Do letramento aos letramentos: desafios na aproximação entre letramento acadêmico e letramento do professor. In: KLEIMAN, A. B.; ASSIS, J. A. (org.). Significados e ressignificações do letramento: desdobramentos de uma perspectiva sociocultural sobre a escrita. Campinas, SP: Mercado das Letras, 2016. 
